\title{
Uma nova espécie do gênero Vestistilus Caldwell, 1949 (Homoptera, Membracidae) ${ }^{1}$
}

\author{
Gabriel Simões de Andrade ${ }^{2}$
}

\begin{abstract}
Vestistilus distinctus $s p . n$. is described from Puerto Quito, Equador.
\end{abstract}

O gênero Vestistilus foi estabelecido por Caldwell, em 1949, para acomodar algumas espécies descritas no gênero Ceresa Amyot \& Serville, 1843. Na revisão da tribo Ceresini, publicada por KOPP \& YONKE (1979), estão incluídas 6 espécies: V. ancora (Ball, 1937), V. nigrovittatus (Fowler, 1895), V. patruelis (Stål, 1864), V. testaceus (Fairmaire, 1846), V. vacca (Fowler, 1895) e V. variabilis (Fowler, 1895). Examinando o material pertencente ao "Museum of Zoology and Entomology", da "Lund University", encontramos 1 exemplar macho e 2 exemplares fêmeas, coletados em Puerto Quito-Equador, que achamos ser uma nova espécie. Examinamos também 1 exemplar fêmea pertencente à coleção do "Museu de Zoologia da Universidade de São Paulo", coletado em Bogotá-Colômbia, que se compara aos exemplares acima referidos.

\section{Vestistilus distinctus sp. $\mathbf{n}$.}

(Figs. 1-6)

Caracteres dianósticos. Coloração geral amarelo-ouro, brilhante; pequenas manchas esparsas no metopídio, no espaço entre os processos supra-umerais, na região posterior do pronoto e duas faixas que partem da região posterior dos processos supra-umerais até o final das impressões semicirculares, brancas. Carena dorsal avermelhada. Ápices dos processos supra-umerais e do pronoto, pretos. Região ventral do corpo amarelada. Tégminas hialinas, veias amarelas nos dois terços basais, mais escurecidas no terço distal.

\footnotetext{
${ }^{1}$ Contribuição' ${ }^{\circ}$. 635 do Departamento de Zoologia da Universidade Federal do Paraná. Caix a Postal, 19020 - 81504, Curitiba - PR, Brasil.

${ }^{2}$ Pós-graduação em Entomologia, Mestrado - UFPR. Bolsista do CNPq.
} 
Medidas (em mm). Macho (holótipo)/fêmea (parátipo). Largura máxima da cabeça: 2,56/2,72; comprimento da cabeça: $1,28 / 1,36$; distância entre os ângulos umerais: 2,48/2,76; distância entre os ápices dos processos supra-umerais: $3,96 / 4,20$; comprimento do pronoto: $6,25 / 6,58$; comprimento total: $6,92 / 7,33$.

Tipos e localidades-tipo: Holotipo macho de "Ecuador: Pichin/Puerto Quito/2.III.1983/leg. L. Huggert". Parátipos: 2 fêmeas, mesmos dados do holo. tipo; 1 fêmea. "Bogotá", "Lindig". O Holótipo e dois parátipos encontram-se depositados no "Museum of Zoology and Entomology" da "Lund University"; um Parátipo fêmea no Museu de Zoologia da Universidade de São Paulo.

Descrição. Holotipo macho. Cabeça duas vezes mais larga que longa; margem superior arqueada, margens laterais sinuosas. Sutura coronal não atingindo a linha imaginária que passa pelo centro dos ocelos. Superfície fracamente estriada. Espaço interocelar convexo, espaço ocelo-ocular deprimido. Lobos supra-antenais escavados. Clípeo piriforme, pouco mais longo que largo, ápice voltado para trás. Pronoto com pontuação fina, mais grossa e profunda nas regiões delimitadas pelas impressões semicirculares e áreas adjacentes a estas. Lobos pós-oculares lisos, transversalmente sulcados. Metopídio convexo; impressões musculares grandes e bem marcadas, em forma de L invertido. Processos supra-umerais oculeados, ápices dirigidos para trás e para cima; espaço entre eles ligeiramente convexo. Impressões semi-circulares bem marcadas, regiões por elas delimitadas, planas. Carena dorsal cortante a partir do ponto mais elevado do pronoto, apenas marcada no metopídio e no espaço entre os processos supra-umerais. Ápice do pronoto ultrapassando a base da terceira célula apical das tégminas. Tégminas com a veia $R_{1}$ originando-se na segunda célula discoidal. Segunda célula discoidal com a forma de um pentágono irregular, tão longa quanto a primeira e com a base peciolada. Célula apical-1 trapezóide, alongada; célula apical-2 diagonalmente transversa; célula apical-3 tão longa quanto a célula apical-1, com a veia $\mathrm{M}_{1+2}$ recurva; célula apical-4 pouco mais curta que a célula apical-5.

Genitália. Edeago subcilíndrico, mais esclerotinizado no terço distal; ápice em forma de gancho, bífido, com as pontas voltadas para a face anterior, lateralmente aparentes em vista posterior; orifício funcional alongado, em forma de uma lança invertida. Parâmeros laminares, membranosos, mais esclerotirizados próximo à articulação com o conectivo. Conectivo anelar, membranoso, com um processo digitiforme de cada lado, dirigidos para trás e situados nas regiões látero-basais. Placas laterais do pigóforo quatro vezes mais longa que largas, pilosas no terço superior, com um pequeno pente de cerdas em destaque inserido no bordo posterior, imediatamente acima do nível da origem do dente lateral; dente lateral maior que a metade do comprimento da placa, lateralmente achatado, cerca de três vezes mais longo que sua largura mediana, com pilosidade esparsa no ângulo póstero-superior; ápice com o aspecto de uma bota, com a ponta mais esclerotinizada e voltada para baixo. Placa subgenital duas vezes mais longa que larga, em vista lateral, pilosa na metade distal, comprimida lateralmente e projetada para baixo; ápice fendido. 
Vol. 6(2), 1989

Fêmea idêntica ao macho no aspecto geral, diferindo apenas por apresentar maiores proporções.

Comentário. As características da genitália do macho distinguem esta espécie de todas as demais. Observamos variações nos parátipos com relação às proporções, ao grau de inclinação dos processos supra-umerais e a distribuição das máculas brancas na região posterior do pronoto.
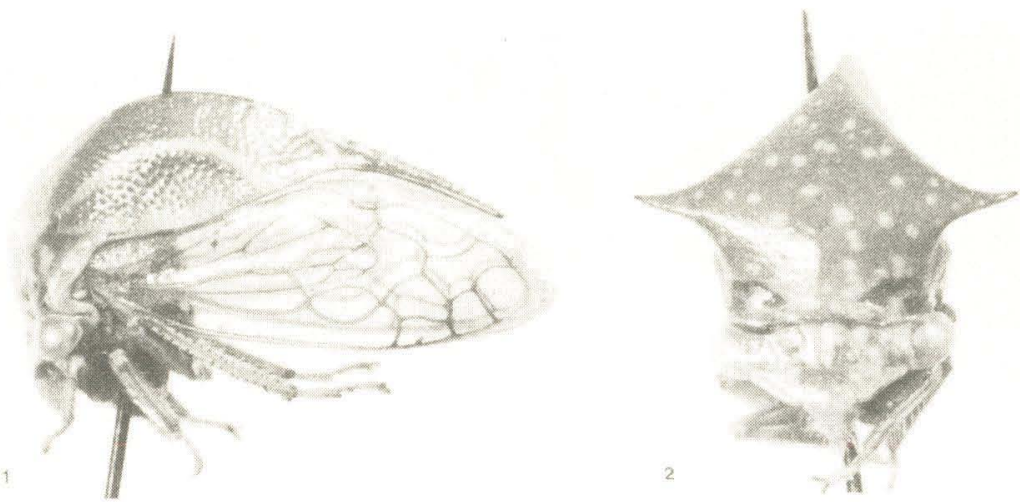

FIGS. 1-2 - Vestistilus distinctus sp. n. (holótipo macho). 1, vista lateral; 2, vista frontal.
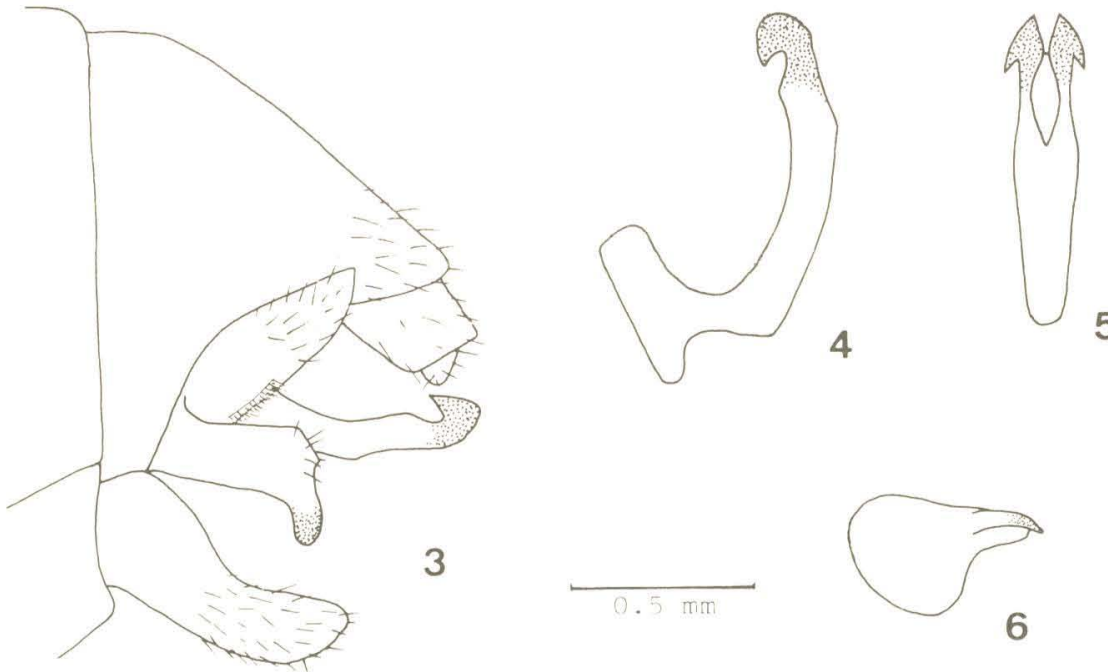

FIGS. 3-6 - Vestistilus distinctus sp. n. (holótipo macho). 3, genitália, vista lateral esquerda; 4 , edeago, vista lateral esquerda; 5 , edeago, vista posterior; 6 , parâmero esquerdo, vista lateral esquerda. 
Revta bras. Zool.

\section{REFERENCIAS}

KOPP, D. D. \& T.R. YONKE. 1979. A tax onomic review of the tribe Ceresini (Homoptera: Membracidae). Misc. Publ. Entomol. Soc. Am., 11 (2): 1-98. 